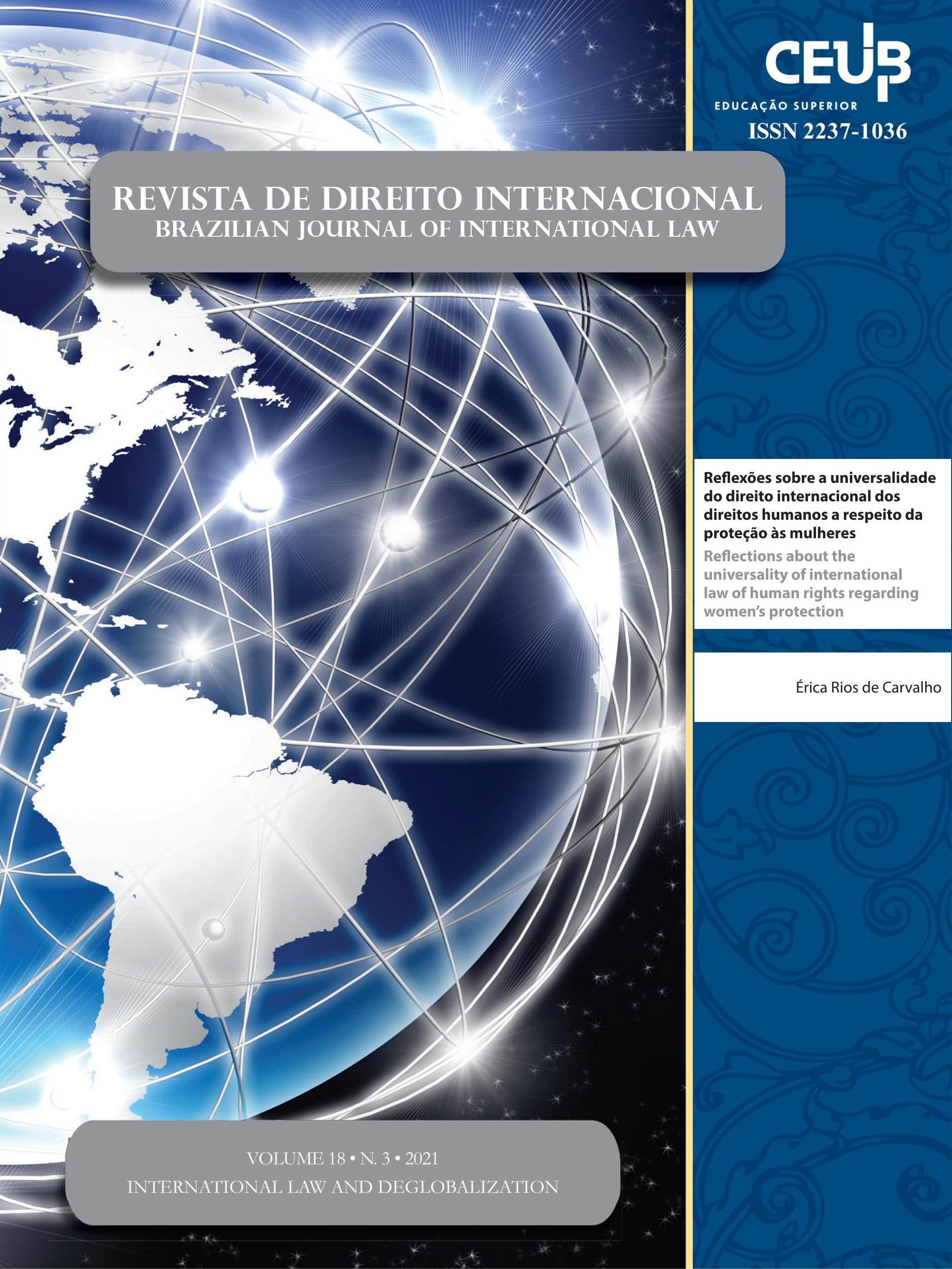




\section{Sumário}

Dossiê

EDITORIAL: INTERNATIONAL LAW AND DE-GLOBALIZATION 16 Ivette Esis, Jaime Tijmes e Juan Enrique Serrano

El régimen jurídico de la Inversión Extranjera Directa: ¿De la limitación a la desGLOBALIZACIÓN?

Ivette Esis Villarroel e Yoselyn Bermúdez Abreu

Desglobalização, Brexit e os novos acordos entre Reino Unido e União Europeia .34 Angela Limongi Alvarenga Alves e Daniel Freire e Almeida

FisCALIDAD Y DESGLOBALIZACIÓN EN UN MUNDO CRECIENTEMENTE UNILATERAL Julio César Muñiz Pérez

Covid, Covax e o Refluxo da Governança Global Salem Hikmat Nasser e Luiza Nogueira Papy

The International Monetary Fund and COVID-19: Old and New Challenges of a Post-World War II INTERNATIONAL INSTITUTION

Virdzhiniya Petrova Georgieva

Artigos Sobre outros temas

RULE OF LAW IN THE INTERNATIONAL ARENA: THE IMPORTANCE OF PRACTICES OF LEGALITY . 112 Angela Jank Calixto

THE WITHDRAWAL OF MEMBER-STATES FROM HUMAN RIGHTS COURTS: IS THE JUDICIALIZATION OF MEGA-POLITICS A NECESSARY CONDITION?. 132

Mikelli Marzzini Lucas Alves Ribeiro e Ernani Rodrigues de Carvalho Neto 
Princípio da precaução e mudança climática: uma análise do Acordo de Paris e das Conferências das Partes.

Jamille Bergamaschine Mata Diz e Carolina Mendonça de Siqueira

A INTERAÇÃo ENTRE OS ESPAÇOS CONSTITUCIONAIS NACIONAIS E INTERNACIONAIS E SEUS IMPACTOS NO SISTEMA DE FONTES DO DIREITO: AS LIÇÕES DA PROTEÇÃO COOPERATIVA DE DIREITOS HUMANOS E O CASO DA INTEGRAÇÃO EUROPEIA ...................................................... 173

Diego Fernandes Guimarães

WTO’s Engagement with National Law: Three Illustrations from India 193 Ravindra Pratap

GESTÃo MIGRATÓRIA E INTEGRAÇÃo REGIONAL: UMA ANÁLISE SOBRE A REGULAMENTAÇÃo NORmativa dos fluxos migratórios irregulares na União Europeia À luz do Novo Pacto Europeu sobre Migração e Asilo.................................................................. 212 João Mauricio Malta Cavalcante Filho e Eugênia Cristina Nilsen Ribeiro Barza

The African Regional Human and Peoples' Rights System: 40 years of progress and CHALLENGES. 232 Juan Bautista Cartes Rodríguez

The USMCA Sunset Clause 258 Jaime Tijmes-Ihl e Yvonne Georgina Tovar Silva

REFLEXÕES SOBRE A UNIVERSALIDADE DO DIREITO INTERNACIONAL DOS DIREITOS HUMANOS A RESPEITO DA PROTEÇÃO ÀS MULHERES 273 Érica Rios de Carvalho

A CRItical legal anAlysis OF GENDER EQUALITY IN INTERNATIONAL TRADE AgREEMENTS...287 Parul Shukla e Sheikh Sultan Aadil Huque

FEMinicídio, FEMicídio E Ódio NA AGENDA: o ASSASSinAto DAS MUlHERES NA AmÉriCA LATINA...... 309 Vinícius Ferreira Baptista

LEGAL IDEOLOGY IN THE CONTEXT OF DEVELOPMENT OF THE LEGAL STATE AND FORMATION OF THE CIVIL SOCIETY IN UKRAINE 
Direito INTERNACIONAL PÚBLICO NO ENTREgUERRAS (1919-39): A INSTITUCIONALIZAÇÃO DOS PROJETOS JURÍDICOS DE PAZ E MANEJO DOS POVOS NÃO SOBERANOS.

Hugo Luís Pena Ferreira

O Caso Gomes Lund (“Guerrilha Do Araguaia”) dez anos depois: Desafios para o cumPRIMENTO INTEGRAL PELO ESTADO BRASILEIRO

João Gabriel Archegas, Felipe Klein Gussoli e Vivian Cristina Lima López Valle

DiÁlogos museológicos: o Regime jurídico brasileiro e o Código de Ética do ConseLHo InTERnacional de Museus.

Paula Gonçalves do Carmo, Emerson Gabardo e Daniel Wunder Hachem 


\title{
Reflexões sobre a universalidade do direito internacional dos direitos humanos a respeito da proteção às mulheres*
}

\author{
Reflections about the universality of \\ international law of human rights regarding \\ women's protection
}

Érica Rios de Carvalho**

\section{Resumo}

Formulou-se este artigo com base no seguinte questionamento de pesquisa: em que medida pode-se observar a universalidade do Direito Internacional dos Direitos Humanos a respeito da proteção às mulheres? O objetivo geral é refletir sobre a aplicabilidade do conceito de universalidade nessa seara, considerando-se a forma de elaboração e aceitabilidade das principais normas internacionais de proteção às mulheres. Para tanto, traçam-se como objetivos específicos identificar o escopo dessas normas no seio da ONU e discutir sua aceitação/rejeição pelos Estados membros. Com base em abordagem metodológica qualitativa, são adotadas as técnicas de revisão bibliográfica e análise documental, em especial dos documentos internacionais identificados como principais pela própria ONU Mulheres. Os resultados indicam a inaplicabilidade do conceito de universalidade em relação ao recorte, diante da insuficiente participação feminina para a elaboração das normas, da sua linguagem androcêntrica e da rejeição dos Estados membros a elas. O trabalho é relevante ao discutir a contraposição entre discursos sobre Direito Internacional dos Direitos Humanos como promessa de aplicação a toda a humanidade e a sua própria construção desigual.

Palavras-chave: universalidade; direito internacional; direitos humanos; proteção às mulheres; normas internacionais.

* Recebido em 21/08/2021

Aprovado em 18/10/2021

** Professora de Direito e Pesquisadora da UCSal. Mestra e Doutora em Políticas Sociais e Cidadania (UCSal). Coordenadora do Núcleo de Pesquisa Conflitos, Estados e Direitos Humanos. Membro da Comissão de Direitos Humanos do Instituto dos Advogados da Bahia. Email: ericariosc@gmail.com

\section{Abstract}

This original paper derives from the research question: to which extent the universality of International Law of Human Rights can be observed under the perspective of women's protection? The main goal is to reflect about the applying of the concept of universality in this area, in view of the international rules of women's protection's writing and acceptance. To reach that goal, the specific objectives are to identify the overlaying of these rules inside the UN and to discuss their acceptance/rejection by the member Stats. From a qualitative approach, the techniques of literature review and document analysis are adopted, especially regarding international documents identified as guidelines by UN Women. Results show the inapplicability of 
the concept of universality in the clipping, in view of the insufficient female participation in writing the rules, their androcentric language and rejection by member States. This paper is relevant by discussing the opposition between the discourses about the International Law of Human Rights as a promise of applicability for all humanity and its own unequal construction.

Keywords: universality; international law; human rights; women's protection; international rules.

\section{Introdução}

Este artigo parte da pergunta de pesquisa: em que medida se pode observar a universalidade do Direito Internacional dos Direitos Humanos a respeito da proteção às mulheres? Assim, o objetivo geral é refletir sobre a aplicabilidade do conceito de universalidade nessa seara, considerando-se a forma de elaboração e aceitabilidade das principais normas internacionais de proteção às mulheres.

Traçam-se como objetivos específicos identificar o escopo dessas normas no âmbito da Organização das Nações Unidas (ONU) e discutir a aceitação/rejeição deste pelos Estados membros, como indicador simbólico da amplitude da aplicabilidade do conceito de universalidade, que é um pressuposto na área do Direito Internacional dos Direitos Humanos.

Com base em abordagem metodológica qualitativa, são adotadas as técnicas de revisão bibliográfica, análise documental e de conteúdo, em especial da Convenção sobre a Eliminação de Todas as Formas de Discriminação Contra a Mulher (ONU, 1979), da Declaração e Plataforma de Ação de Beijing (ONU, 1995) e da Resolução 1325/2000 do Conselho de Segurança da ONU sobre Mulheres, Paz e Segurança ${ }^{1}$. Tais documentos foram destacados para análise por serem as mais relevantes e atuais em relação à ONU acerca da proteção às mulheres, o que se comprova pela identificação da própria ONU Mulheres como sendo seus parâmetros ou documentos-guia. ${ }^{2}$

\footnotetext{
1 O Brasil, por enquanto, não internalizou essa norma em seu ordenamento jurídico. Em 2012, o Ministério da Defesa assinou uma Carta de Intenções perante a ONU Mulheres, porém não houve encaminhamento posterior. Fonte: http://www.onumulheres.org.br/ areas-tematicas/paz-e-seguranca/. Acesso em: 02 mar. 2021.

${ }^{2}$ Disponível em: Guiding documents | UN Women - Headquar-
}

Há pouca produção científica brasileira sobre o tema proposto, o que se verifica com base na consulta à base SciElo, considerando-se as palavras-chave "Direito Internacional" e "Mulheres". Obtiveram-se, apenas, sete resultados. Dentre eles, apenas um contém análise próxima da ora proposta, acerca de limitações da própria área em enxergar e combater as muitas discriminações que atingem as mulheres, incluindo a dificuldade de abertura interseccional. Consultando-se as palavras-chave "Direito Internacional" + "Direitos Humanos" e "universalidade", apenas um resultado foi encontrado na plataforma SciElo - incorporou-se este à revisão bibliográfica em virtude de sua pertinência para este estudo.

Alterando-se as palavras-chave para "Direitos Humanos" + "mulheres" + "universalidade", retornaram-se dois resultados, sem relação com o objeto de estudo proposto neste artigo. Em relação à consulta dos termos "mulheres" + "universalidade", como palavras-chave, a plataforma encontrou somente 10 trabalhos, dois deles já presentes nas buscas anteriores, um específico da área de saúde e nenhum dos demais se relacionava, diretamente, ao objeto proposto. Por fim, destaque-se que vários dos resultados encontrados não eram produções brasileiras. Outrossim, a presente pesquisa se justifica à luz desse cenário de baixa produção acadêmica nesse âmbito crítico.

Para alcançar os objetivos propostos, primeiramente, é fundamental definir o que se entende como "universalidade". Por coerência com o sistema internacional de direitos humanos, este artigo adota a definição conforme construída nos artigos 1 e 2 da Declaração Universal de Direitos Humanos (DUDH - ONU, 1948):

\begin{abstract}
Artigo 1
Todos os seres humanos nascem livres e iguais em dignidade e direitos. São dotados de razão e consciência e devem agir em relação uns aos outros com espírito de fraternidade.

Artigo 2

1. Todo ser humano tem capacidade para gozar os direitos e as liberdades estabelecidos nesta Declaração, sem distinção de qualquer espécie, seja de raça, cor, sexo, língua, religião, opinião política ou de outra natureza, origem nacional ou social, riqueza, nascimento, ou qualquer outra condição.
\end{abstract}

ters. Acesso em: 14 mar. 2021. A ONU Mulheres também adota os Objetivos do Desenvolvimento Sustentável como guia, mas por não possuir recorte específico nas mulheres, esse documento foi descartado no critério para este artigo. 
2. Não será também feita nenhuma distinção fundada na condição política, jurídica ou internacional do país ou território a que pertença uma pessoa, quer se trate de um território independente, sob tutela, sem governo próprio, quer sujeito a qualquer outra limitação de soberania.

Entretanto, as previsões da Carta da ONU, da DUDH (desde seu preâmbulo), repetidas nos primeiros artigos de praticamente todos os tratados internacionais, sobre sermos todos iguais (povos; homens e mulheres; pessoas de qualquer raça/etnia/cor, nacionalidade, crença, orientação sexual etc.) não necessariamente se transpõem da esfera discursiva-normativa para a esfera prática. Isso fica exposto com base em um olhar decolonial crítico, com recortes como raça, gênero e classe. Neste trabalho, adota-se o recorte de gênero, considerando-se, especificamente, as mulheres, com base nos dados concretos que serão trazidos no desenvolvimento deste trabalho sobre a continuada desigualdade de entre homens e mulheres em todo o mundo. ${ }^{3}$

Outro conceito central neste trabalho é o de comunidade epistêmica ${ }^{4}$. Ele significa que, mediante processos e recursos ideológicos, os profissionais, intelectuais e instituições (incluindo os Estados nacionais e o mercado) compõem um conjunto de crenças que constituem fundamentos morais, políticos e, disfarçadamente, econômicos para balizar uma espécie de consenso coletivo (relativo). A considerar os discursos do Direito Internacional dos Direitos Humanos como uma comunidade epistêmica, que discussões emergem acerca da sua suposta universalidade?

Nesse sentido, cabe a ponderação, proposta neste artigo, sobre a construção das normas, relativas ao Direito Internacional dos Direitos Humanos e sua suposta universalidade, especificamente a respeito da proteção das mulheres.

\footnotetext{
${ }^{3}$ Não se ignora, portanto, que haja outras identidades de gênero para além da divisão binária entre homens e mulheres, tipicamente europeia ocidental. Contudo, em nome de viabilidade, neste artigo, elegeu-se trabalhar, apenas, com base nos limites da hegemônica divisão binária, que se reproduz na sociedade internacional.

${ }^{4}$ HAAS, Peter M. Epistemic communities and international policy coordination. International Organization, v. 46, n. 1, p. 1-35, 1992. Disponível em: https://www.jstor.org/stable/2706951. Acesso em: 20 jul. 2021 .
}

\section{Desenvolvimento e resultados}

Diante de uma suposição geralmente aplicada de forma acrítica pelos juristas de que há um consenso universal sobre certos valores, faz-se necessário verificar se a universalidade de direitos humanos resultante dessa linha de pensamento se concretiza na prática. Há divergência sobre a necessidade ou até mesmo relevância de se fundamentar de forma absoluta os direitos humanos. Há duas matrizes discutindo o tema, a saber, a objetivista e a subjetivista.

A matriz objetivista prega a existência de fundamentos, valores per si, que há universal, absoluta e objetivamente, ou seja, são um conhecimento a priori, "possuem validez [...] independentemente da experiência dos indivíduos ou de sua consciência valorativa." ${ }^{5}$

Por outro lado, a matriz subjetivista, representada por Bobbio $^{6}$, afirma que é vã e inútil qualquer tentativa de fundamentar os direitos humanos, já que os fundamentos podem variar conforme o direito, o contexto e os interlocutores. Ademais, o que importa é a efetivação dos direitos, não seu fundamento.

Se considerada a construção do Direito Internacional dos Direitos Humanos como uma comunidade epistêmica ${ }^{7}$, pode-se acompanhar a ponderação de Bobbio ${ }^{8}$ a respeito da estruturação que os direitos humanos, na sociedade jurídica internacional, trazem, como o fato de terem como algumas de suas características serem históricos e relativos ${ }^{910}$. Assim, trata-se de uma construção sempre inacabada, um produto da experiência humana. ${ }^{11}$

Dessa maneira, esse conjunto de crenças, erigidas na sociedade internacional (a chamada comunidade epistêmica), a balizar essa espécie de consenso coletivo sobre o Direito Internacional dos Direitos Humanos, embora seja de partida relativo, carece de mais apurado exame.

\footnotetext{
5 DUARTE, 2002, apud SILVA, F. D. L.; I. FILHO, R. M.; SILVA, R. L. Direitos bumanos. Rio de Janeiro: SESES, 2016. p. 19.

${ }^{6}$ BOBBIO, Norberto. A era dos direitos. São Paulo: Campus, 2004.

7 HAAS, Peter M. Epistemic communities and international policy coordination. International Organization, v. 46, n. 1, p. 1-35, 1992. Disponível em: https://www.jstor.org/stable/2706951. Acesso em: 20 jul. 2021.

8 BOBBIO, Norberto. A era dos direitos. São Paulo: Campus, 2004.

9 ONU. Conferência mundial sobre direitos humanos. Viena, 1993.

10 Dentre outras características, como a própria pressuposta universalidade.

${ }^{11}$ HUNT, Lynn. A invenção dos direitos humanos: uma história. São Paulo: Companhia das Letras, 2009.
} 
Será que se verifica de fato a universalidade dessa comunidade epistêmica? Ao se construir um tal consenso relativo, surge de imediato o questionamento sobre quem fica dele excluído. Quem são as pessoas marginalizadas, fora dessa construção e, portanto, desafiando de partida a suposição de universalidade do Direito Internacional dos Direitos Humanos?

Esse quase-consentimento se constrói como uma forma de hegemonia, parte de um acordo entre agentes globais. Diz-se "quase" e relativiza-se o consenso porque os agentes que têm voz ativa e determinante nesse processo de construção da comunidade epistêmica são, historicamente, do Norte global. Ao Sul, resta consentir, aderir, obedecer, se adequar... sob ameaças nem sempre tão implícitas de exclusão das trocas econômicas internacionais. ${ }^{12}$

[...] a mera afirmação de que os direitos humanos são inerentes a todos os seres humanos não garante sua imediata adoção por todas as comunidades. Não só há um considerável hiato entre os lugares onde premissas universais são criadas e as condições particulares onde elas devem ser implementadas, como também existe uma distância entre a implementação teórica de padrões de direitos humanos por Estados e sua regulação prática do comportamento de atores privados. ${ }^{1314}$

A respeito dessa comunidade epistêmica, nesse grande, mas relativo consenso, se fala em universalizar os direitos humanos. A primeira norma dita universal sobre tais direitos era intitulada "Declaração Universal dos Direitos do Homem", de 1948, reproduzindo a menos universal ainda Declaração de Direitos do Homem e do Cidadão da Revolução Francesa. À mesma época, as mulheres que se atreveram a redigir a Declaração de

\footnotetext{
12 Essa discussão foi feita de forma mais ampla e aprofundada na tese de doutorado de CARVALHO, Érica Rios de. Direitos humanos e dominação: a ONU no espelho. 2019. Tese (Doutorado em Políticas Sociais e Cidadania) - Universidade Católica do Salvador, Salvador, 2019.

13 KROETZ, Flávia Saldanha. Between global consensus and local deviation: a critical approach on the universality of human rights, regional human rights systems, and cultural diversity. Revista de Investigações Constitucionais, v. 3, n. 1, p. 43-58, 2016. p. 45. Disponível em: https://revistas.ufpr.br/rinc/article/view/45109. Acesso em: 15 mar. 2021.

14 Tradução livre da autora a partir do original: "[...] the mere assertion that human rights are inherent to every human being does not guarantee their immediate embracement by all communities. Not only there is a considerable gap between the places where universal assumptions are framed and the particular condi- tions in which they are to be implemented, but also a distance between the theoretical implementation of human rights standards by States and their practical regulation of the behaviour of private actors."
}

Direitos da Mulher e da Cidadã, em resposta direta ao que consideraram inadequação e injustiça da Declaração de Direitos do Homem e do Cidadão, foram rapidamente guilhotinadas e o referido documento foi esquecido pela história hegemônica. ${ }^{15}$

Assim, o tensionamento sobre "homem" pode ser admitido como paradigma universal. Já existia há alguns séculos, mesmo na hegemônica Europa ocidental, mesmo na colonizadora França. Portanto, os questionamentos atuais sobre a desigualdade de acesso das mulheres aos espaços onde se redige o Direito, onde se anuncia o reconhecimento dos direitos e seus titulares, não surgiram de forma repentina. As mulheres já vêm tensionando essa suposta universalidade há séculos.

Somente em 1979 as Nações Unidas redigiram a "Convenção sobre a eliminação de todas as formas de discriminação contra a mulher" (CEDAW), de protocolo facultativo. Ou seja, apenas ao final do século XX, a sociedade internacional se debruçou sobre o problema da desigualdade entre homens e mulheres no mundo. Mesmo assim, ela o fez com base em um protagonismo de representantes estatais masculinos, com olhar eurocentrado e parcial sobre o tema.

Nesse sentido, até o fechamento deste artigo, não havia sido ultrapassada a visão de gênero como oposição binária estrita entre homem e mulher, mantendo-se a invisibilidade sobre outros gêneros, performances e a necessária distinção entre gênero e orientação sexual, por exemplo. ${ }^{16} \cdot{ }^{17}$ (Embora o recorte deste trabalho sejam as mulheres, essa ressalva precisava ser feita.)

${ }_{15}$ HUNT, Lynn. A invenção dos direitos humanos: uma história. São Paulo: Companhia das Letras, 2009.

16 BUTLER, Judith. Actos performativos y constitución del género: un ensayo sobre fenomenologia y teoría feminista. In: CASE, SueEllen (org.). Performing feminisms: feminist critical theory and theatre. [s.l.]: Johns Hopkins University Press, 1990. p. 270-282; BUTLER, Judith. Gender trouble: feminism and the subversion of identity. New York: Routledge, 1990.

17 Até o presente momento, não há nenhum tratado internacional que proteja especificamente as minorias assim identificadas por sua diversidade de gênero, orientação sexual e/ou performance. Apesar de se poder argumentar que essas pessoas estariam contempladas por todas as normas de direitos humanos que afirmam a igualdade de todas, independentemente de qualquer circunstância ou característica individual ou coletiva, na prática trata-se de grupo altamente violentado no mundo todo. $\mathrm{O}$ único documento formal de alcance internacional sobre sua proteção específica é o chamado de "Princípios de Yogyakarta", elaborado por pesquisadores, organizações não governamentais e ativistas em resposta justamente à ausência de conferências e tratados internacionais sobre o tema. Disponível em: http://www.dhnet.org.br/direitos/sos/gays/principios_de_yo- 
Mesmo com sua incompletude e baixa representatividade feminina no processo de elaboração, a CEDAW conta, atualmente, com 181 Estados-partes. É um elevado número de aceitação a priori, porém mais de 50 países que ratificaram a convenção sujeitaram a ratificação a declarações, reservas e objeções. Essa norma foi a que recebeu o maior número de reservas por parte dos Estados, dentre todos os tratados internacionais de direitos humanos. Isso quer dizer que há uma relevante resistência internacional a seu conteúdo, ainda que em parte.

Nessa lista de reservas, incluem-se 38 países que rejeitaram o artigo 29, que trata de meios de resolução de litígios relativos à interpretação ou aplicação da Convenção. Ao impor uma reserva a esse dispositivo, muito da coercibilidade do tratado se torna vazia, uma vez que não ficam previstos mecanismos ou órgãos internacionais para decisões acerca de conflitos como, por exemplo, acusações de descumprimento dessa norma em específico por aquele Estado que impôs a restrição.

Nunca é demais destacar que países de diversas culturas, formações étnicas e bases religiosas impuseram restrições a trechos do tratado em tela. Não é possível atribuir a determinada religião, etnia ou cultura a explicação por tal rejeição, exceto se for admitido um elemento comum a todas essas.

Mapa 1 - Participação na Convenção sobre a Eliminação de Todas as Formas de Discriminação contra a Mulher (CEDAW)

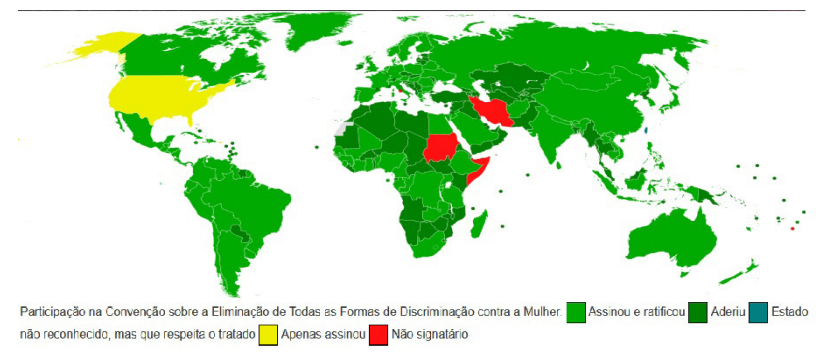

Fonte: Wikimedia Commons, 2008. Disponível em: https:// commons.wikimedia.org/wiki/File\%3ACEDAW_Participation.svg. Acesso em: 12 mar. 2021.

De acordo com dados oficiais da $\mathrm{ONU}^{18}$, um elevado número de reservas concentrou-se na cláusula referente à igualdade entre mulheres e homens na família.

gyakarta.pdf. Acesso em: 20 ago. 2021.

18 Registros da Convenção Sobre a Eliminação de Todas as Formas de Discriminação contra as Mulheres, ONU. Disponível em: http:/ / www.un.org/womenwatch/daw/cedaw/reservations-country.htm. Acesso em: 28 maio 2016.
Tais reservas foram justificadas com base na ordem religiosa, cultural ou mesmo legal dos países que assim as impuseram. Segundo Santo ${ }^{19}$, houve países, como Bangladesh e Egito, que acusaram o Comitê sobre a Eliminação da Discriminação contra a Mulher de praticar "imperialismo cultural e intolerância religiosa", ao infundir a ideia de igualdade entre homens e mulheres, até mesmo na família.

Por mais que se questione essa indignação face à mera ideia de igualdade entre homens e mulheres no seio familiar, críticas de países do Sul global, fundamentadas num olhar eurocentrado, ocidentalizado, sem abertura a um diálogo verdadeiramente intercultural, são recorrentes no Direito Internacional dos direitos humanos. ${ }^{20}$

Ademais, a CEDAW sofre críticas por abordar a mulher como um ser abstrato e monolítico, sem contemplar as peculiaridades das vidas femininas em diferentes contextos geográficos, étnicos, religiosos, políticos, etários, de orientação sexual etc. ${ }^{21}$. Entretanto, Campbell ${ }^{22}$ comenta que o Comitê CEDAW vem adotando práticas pioneiras, dentro do seio da ONU, em busca de enxergar e atuar face às interseccionalidades nesse sentido. Não obstante tais esforços, ainda resta muito a fazer para que resultados práticos transformativos sejam vistos.

A CEDAW propõe a eliminação de todas as formas de discriminação para que se alcance a igualdade entre homens e mulheres, de forma que todas elas possam gozar de seus direitos humanos. Campbell ${ }^{23}$ argumenta que isso inclui, implicitamente, o compromisso de compreender e abordar a discriminação interseccional ${ }^{24}$.

192006 apud Registros da Convenção Sobre a Eliminação de Todas as Formas de Discriminação contra as Mulheres, ONU. Disponível em: http://www.un.org/womenwatch/daw/cedaw/reservationscountry.htm. Acesso em: 28 maio 2016.

${ }^{20}$ SANTOS, Boaventura de Sousa. A gramática do tempo: para uma nova cultura política. Porto: Afrontamento, 2006. p. 401-435.

${ }^{21}$ CHINKIN, Christine; FREEMAN, Marsha. Introduction. In: FREEMAN, Marsha; CHINKIN, Chrstine; RUDOLF, Beate (org.). The UN Convention on the Elimination of All Forms of Discrimination Against Women: a commentary. [s.l.]: OUP, 2013.

${ }^{22}$ CAMPBELL, Meghan. CEDAW and women's intersecting identities: a pioneering new approach to intersectional discrimination. Revista Direito GV, v. 11, n. 2, p. 479-504, 2015. p. 483.

${ }^{23}$ CAMPBELL, Meghan. CEDAW and women's intersecting identities: a pioneering new approach to intersectional discrimination. Revista Direito GV, v. 11, n. 2, p. 479-504, 2015.

24 Para melhor compreensão sobre interseccionalidade, vide AKOTIRENE, Carla. Interseccionalidade. São Paulo: Pólen, 2019. 
As mulheres experimentam desvantagem e discriminação com base no seu sexo e gênero, mas isso também está intrinsecamente ligado a outras identidades, fatores e experiências, tais como raça e pobreza. Sob a perspectiva do CEDAW, se sexo e gênero são uma das bases para a discriminação, é necessário examinar como outras identidades e fatores contribuem para a discriminação de gênero e desigualdade. O Comitê CEDAW tem sido pioneiro nessa abordagem nas recomendações gerais, comunicações individuais, inquérito e observações finais, mas não tem consistentemente aplicado esta abordagem fluida e expansiva. ${ }^{25}$

Já em relação à Declaração e Plataforma de Ação de Beijing (ONU, 1995), a adesão inicial foi bem maior. De partida, já contava com 189 países. O tratado passou por revisões e ajustes desde então, sendo a versão mais clara e extensiva, dentre os documentos internacionais de proteção às mulheres, no sentido de propor a busca pelo empoderamento feminino e pela libertação de opressões de múltiplas fontes. Nessa linha, abrange as áreas de saúde, violência, conflitos armados, economia, poder e tomada de decisões, mecanismos institucionais, direitos humanos, mídia, meio ambiente e meninas.

A declaração é considerada pelo Brasil ${ }^{26}$ como a mais completa sobre proteção às mulheres, pois incorpora tratados anteriores, como a DUDH (ONU, 1948) e a Declaração sobre a Eliminação da Discriminação contra a Mulher, produzido pelo Comitê sobre Discriminação contra a Mulher da Organização das Nações Unidas (ONU, 1979).

O próprio documento ${ }^{27}$ informa que mais de $30 \mathrm{mil}$ pessoas participaram das discussões na $4^{\mathrm{a}}$ Conferência Mundial sobre Mulheres, em 1995, levando ao mencionado tratado. Entretanto, não pondera que a maioria dos representantes dos Estados presentes eram homens.

Durante a IV Conferência Mundial sobre a Mulher, em 1995, quando foi aprovada a Declaração de Beijing, os governos participantes se comprometeram a cumprir, até o final do século XX, as estratégias acordadas no Quênia em 1985. Combinaram que iriam mobilizar recursos para a implementação da Plataforma de Ação, também assinada naquele momento.

25 CAMPBELL, Meghan. CEDAW and women's intersecting identities: a pioneering new approach to intersectional discrimination. Revista Direito GV, v. 11, n. 2, p. 479-504, 2015. p. 479.

${ }^{26}$ Fonte: Câmara dos Deputados. Brasília, 2021. Disponível em: Declaração de Beijing - Notícias - Portal da Câmara dos Deputados (camara.leg.br). Acesso em: 14 mar. 2021.

${ }^{27}$ Disponível em: pfa_e_final_web.pdf (unwomen.org). Acesso em: 14 mar. 2021.
Mais de 20 anos após a sua adoção, nenhum país do mundo atingiu a equidade entre homens e mulheres ${ }^{28}$, o que diz bastante sobre a inefetividade do tratado. Aliás, o mero fato de a Declaração, em 1995, retomar compromissos assumidos 10 anos antes (na Conferência de Nairóbi, de 1985), e ainda não cumpridos, já é um indicativo simbólico, que não pode ser esquecido, sobre qual é, de fato, o compromisso e o grau de prioridade que a pauta da proteção às meninas e mulheres tinha nas agendas de cada Estado, bem como na internacional.

A Plataforma de Ação adotada em 1995 atribuiu aos governos, aos organismos internacionais e à sociedade civil a responsabilidade de construir um mundo de justiça e igualdade. Entre eles, a Câmara dos Deputados do Brasil $^{29}$ destaca:

o estabelecimento, ampliação e fortalecimento de sistemas de análise da situação das mulheres e de dados estatísticos em todas as áreas, e sua ampla divulgação; o planejamento, estabelecimento e implementação de programas e políticas públicas que leve em consideração a situação de mulheres e homens, em razão da construção cultural e social das desigualdades; a atualização e propostas de novas legislações de combate à discriminação da mulher em todos os âmbitos; e a promoção da igualdade, incluindo ações afirmativas para acesso a cargos públicos e de decisão e a mandatos efetivos, além de oportunidades no mundo do trabalho.

Não obstante, o texto da Declaração e da sua Plataforma (ONU, 1995) contém expressões genéricas (como, aliás, é típico de tratados internacionais sobre direitos humanos, a fim de diminuir o índice de rejeição a eles) e não propositivas, como o ponto 22 da Declaração, que fala que os países membros estão determinados a intensificar esforços e ações para alcançar os objetivos da Convenção de Nairóbi (ONU, 1985) até o final do século XX; ou o ponto 28 , que aponta a determinação dos referidos Estados membros a "tomar passos positivos para garantir paz para o avanço das mulheres". Esse mesmo ponto fala, ainda, em "agir ativamente em direção ao geral e completo desarmamento sob estrito e efetivo controle internacional" - o que incluiria o sucesso das longas tratativas e a adoção de um tratado que banisse testes nucleares e promovesse desarmamento nuclear. ${ }^{30}$

\footnotetext{
${ }^{28}$ Disponível em: pfa_e_final_web.pdf (unwomen.org). Acesso em: 14 mar. 2021.

${ }^{29}$ Fonte: Câmara dos Deputados. Brasília, 2021. Disponível em: Declaração de Beijing - Notícias - Portal da Câmara dos Deputados (camara.leg.br). Acesso em: 17 mar. 2021.

${ }^{30}$ O Tratado de Proibição de Armas Nucleares entrou em vigor
} 
Já passados mais de 20 anos do fim do século XX, que era o marco temporal previsto para que a Plataforma de Ação de Beijing fosse inteiramente cumprida, não se pode apontar um único item da proposta que tenha sido efetivamente alcançado no mundo como um todo. Dados sobre a continuidade da desigualdade entre homens e mulheres demonstram o fracasso dessas ações, tanto no âmbito econômico (diferenças salariais, por exemplo) quanto em relação ao acesso à participação política, acesso a direitos humanos (mulheres e meninas são as mais atingidas negativamente pela pandemia da COVID-19, por exemplo), falta de autonomia individual, sexual e reprodutiva etc. ${ }^{31}$

Destacam-se os seguintes pontos, apenas exemplificativamente, para se verificar a inefetividade da adesão de quase todos os países do mundo aos tratados mencionados: (i) mulheres são menos de $24 \%$ dos parlamentares e menos de $5 \%$ dos prefeitos do mundo; (ii) em média, mulheres recebem $24 \%$ menos do que homens por trabalhos equivalentes, em todas as regiões e setores profissionais do mundo; (iii) quase $2 / 3$ dos analfabetos adultos do mundo são mulheres - proporção que permanece inalterada há mais de 20 anos; (iv) 153 países têm leis que discriminam, economicamente, as mulheres, incluindo 18 Estados onde é permitido que os maridos impeçam as esposas de trabalharem; e (v) em todo o mundo, uma em cada três meninas e mulhe-

apenas em 2021, e, mesmo assim, com baixa adesão. Somente 51 países ratificaram o tratado, sendo que nenhum deles é uma potência nuclear. Até mesmo o Brasil, que foi o primeiro a assiná-lo em 2017, ainda não ratificou o documento. Nesse sentido de rejeição, são constantes os descumprimentos de Rússia e EUA em relação às promessas e tratados de desarmamento nuclear. A título de exemplo: BAND JORNALISMO. EUA anuncia saida de tratado de desarmamento nuclear. 02 ago. 2019. Disponível em: https://youtu.be/ LwFe23BCwmQ. Acesso em: 17 mar. 2021.

${ }^{31}$ UN WOMEN. 2019-2020 Families in a changing world. New York, 2021. Disponível em: https://www.unwomen.org/-/media/headquarters/attachments/sections/library/publications/2019/poww2019-fact-sheet-global-en.pdf?la=en\&vs=0. Acesso em: 20 ago. 2021; RHODES, F.; BURNLEY, J.; DOLORES, M. Underpaid and undervalued: how inequality defines women's work in Asia'. Oxford: OXFAM, 2016. Disponível em: http://policy-practice.oxfam.org. uk/publications/underpaid-and-undervalued-how-inequalitydefines-womens-work-in-asia-611297. Acesso em: 20 ago. 2021; OXFAM. 5 ways women and girls have been the hardest bit by Covid-19. 2021. Disponível em: https://www.oxfam.org/en/5-ways-womenand-girls-have-been-hardest-hit-covid-19. Acesso em: 20 ago. 2021; UN WOMEN. Report of the Secretary-General (2019): why addressing women's income and time poverty matters for sustainable development. New York, 2019. Disponível em: https://www.unwomen. org/en/digital-library/publications/2019/06/world-survey-on-therole-of-women-in-development-2019. Acesso em: 20 ago. 2021. res já sofreram ou sofrerão violência ou abuso ao longo da sua vida. ${ }^{32}$

Nesse contexto, outro documento internacional que precisa ser comentado é a Resolução 1325/2000 33 do Conselho de Segurança da ONU sobre Mulheres, Paz e Segurança ${ }^{34}$. Por um lado, ela representa avanços em termos históricos e de agenda, no sentido de abrir possibilidades para um lugar reconhecido para as mulheres em processos de construção da paz, proteção das violações dos direitos humanos e promoção do acesso à justiça e aos serviços para enfrentar a discriminação. Elas são ali tratadas como pessoas com voz e protagonismo próprios. Por outro, concepções de gênero problemáticas são reproduzidas no texto da Resolução.

[...] apesar de bem-intencionada, a Resolução ajudou a inscrever, institucionalizar e reproduzir assunções e conceitos que condicionam a própria busca de igualdade de género, paz e segurança a nível nacional e internacional. A Resolução é assim apenas um passo inicial rumo ao reconhecimento das conexões entre género, violência e segurança, mas a sua direção não transforma os entendimentos sobre cada um dos conceitos nem as suas articulações no seio das Nações Unidas, dos Estados-membros e das próprias organizações não-governamentais dedicadas às questões de género, nomeadamente os grupos de mulheres. [...] As limitações da 1325 [...] estão relacionadas com: 1) a noção de género aí veiculada (centrando-se nas mulheres e sobretudo nas mulheres como vítimas ou fazedoras de paz); 2) a concepção dos momentos de ameaça exclusivamente como momentos de guerra ou períodos dela derivados (pós-guerra), geralmente tendo em conta o curto prazo e não os processos mais latos de reprodução da violência); 3) e a concepção de segurança como algo que os centros garantem às periferias (sem agência) através de políticas de tom paternalista, como o aumento da representação e participação das mulheres a todos os níveis de tomada de decisão dos processos de resolução de conflitos, reconstrução pós-guerra e construção da paz, e interseccionalidade de género, ou ainda, políticas repressivas. ${ }^{35}$

32 OXFAM. Gender justice and women's rights. 2021. Disponível em: https://www.oxfam.org/en/what-we-do/issues/gender-justiceand-womens-rights. Acesso em: 20 ago. 2021.

33 Disponível na íntegra em: http://www.igualdade.gov.pt/images/ stories/Area_Internacional/ONU/resolucao $\% 201325 \% 20$ portugues.pdf. Acesso em: 02 jan. 2021.

${ }_{34} \mathrm{O}$ Brasil, por enquanto, não internalizou esta norma em seu ordenamento jurídico. Em 2012, o Ministério da Defesa assinou uma Carta de Intenções perante a ONU Mulheres, porém não houve encaminhamento posterior. Fonte: http://www.onumulheres.org.br/ areas-tematicas/paz-e-seguranca/. Acesso em: 02 jan. 2021.

35 SANTOS, Rita; ROQUE, Sílvia; MOURA, Tatiana. Conexões perdidas: representações de género, violência (armada) e segurança na Resolução 1325. Revista Crítica de Ciências Sociais, n. 96, p. 165-196, 
$\mathrm{Na}$ referida resolução, as mulheres são reafirmadas como "a grande maioria" das vítimas dos conflitos armados, sem qualquer comprovação empírica. O texto cristaliza a imagem da mulher como vítima, negligenciando seus eventuais contributos para a violência e sua própria capacidade de agência e estratégia. Também é firmada sua figura de mediadora informal, pacificadora e cuidadora. (Op. cit.), como se toda mulher fosse naturalmente pacifista e tivesse um dom nato para a função maternal/cuidadora. Quem se beneficia de reiterar essas visões sobre as mulheres e sua posição social?

A resolução ignora, também, que o maior risco para as mulheres não é durante a guerra, mas em tempos de paz formal, diante dos altíssimos números de mortes por violência de gênero, doméstica e/ou da intimidade. Segundo a Organização Pan-Americana de Saúde (OPAS) $)^{36}$, a maior parte dos casos é de violência infligida por parceiros. Em todo o mundo, quase um terço $(30 \%)$ das mulheres que estiveram em um relacionamento relatam ter sofrido alguma forma de violência física e/ou sexual na vida por parte de seu parceiro. Estimativas globais publicadas pela Organização Mundial da Saúde (OMS) indicam que, aproximadamente, uma em cada três mulheres $(35 \%)$ em todo o mundo sofreram violência física e/ou sexual por parte do parceiro ou de terceiros durante a vida. ${ }^{37}$

Inclusive, de acordo com o relatório "The Global Burden of Armed Violence"3839, a maior parte da violência letal e não letal contra mulheres e meninas ocorre em zonas e momentos de paz formal. Porém as situações de conflito lhes acrescentam uma camada de vulnerabilização, pois elas passam a ficar, ainda mais expostas, a morrer vítimas das violências de gênero, doméstica e da intimidade através do uso de armas de fogo. Além disso, em conflitos armados, o risco de serem repetidamente

2012. p. 168-169.

36 Disponível em: https://www.paho.org/bra/index.php?option=com_ content\&view $=$ article\&id $=5669$ : folha-informativa-violencia-contra-asmulheres\&Itemid=820. Acesso em: 20 mar. 2021.

${ }^{37}$ Disponível em: https://www.paho.org/bra/index.php?option=com_ content\&view $=$ article\&id $=5669$ : folha-informativa-violencia-contra-asmulheres\&Itemid=820. Acesso em: 20 mar. 2021.

38 GENEVA DECLARATION. Lethal violence against women and girls. The Global Burden of Armed Violence, p. 87-120, 2015. Disponível em: http://www.genevadeclaration.org/measurability/global-burden-of-armed-violence/global-burden-of-armed-violence-2015.html. Acesso em: 20 ago. 2021.

39 Disponível na íntegra em: http://www.genevadeclaration.org/ measurability/global-burden-of-armed-violence/global-burden-ofarmed-violence-2015.html. Acesso em: 02 jan. 2021. vítimas dessas violências aumenta. Não obstante, quantas mulheres e meninas são diariamente feridas física e emocionalmente na "segurança" de suas próprias casas, fora de zonas de guerra? O relatório afirma não haver dados sobre as ameaças e humilhações mediante arma de fogo em casa; tampouco sobre a violência com uso de armas brancas.

Os muitos e alarmantes dados sobre violência doméstica e da intimidade com armas de fogo dentro de casa não são o alvo da Resolução 1325/2000, que frisa se tratar de conflitos armados, mas é preciso chamar atenção para mais uma norma internacional que silencia sobre a microviolência - micro porque no ambiente doméstico, mais uma vez invisibilizado, tido como sem valor. É a mesma lógica da dissociação-valor ${ }^{40}$ ou das mulheres como segundo sexo ${ }^{41}$, ou seja, o trabalho de cuidados domésticos e de familiares, feito geralmente pelas mulheres, é dissociado de valor, em virtude de ser executado em ambiente privado e sem remuneração financeira direta. Invisibilizado e desvalorizado, porém fundamental para a reprodução social no capitalismo. Esse olhar sobre o trabalho insere as mulheres em uma posição aparentemente secundária na sociedade.

As mulheres não estão mais vulneráveis durante a guerra, mas sim se tornam mais vulneráveis pelas desigualdades preexistentes em sociedades que se dizem pacíficas, decorrentes de hierarquias de poder de gênero. ${ }^{4243}$

Por outro lado, os homens não são referidos de forma clara em nenhum ponto da Resolução 1325/2000.

\begin{abstract}
Ao ignorar as experiências de outras mulheres e outros homens dentro de distintas estruturas de diferenciação social (como por exemplo classe, etnia, nacionalidade, orientação sexual e idade), a Resolução 1325 pode também ser considerada uma reprodução da dominação de "feminismo branco, ocidental e heterossexual." O silêncio da 1325 sobre as estruturas de poder nacionais, locais e glo-
\end{abstract}

40 SCHOLZ, Roswitha. O valor é o homem: teses sobre a socialização pelo valor e a relação entre os sexos. Novos Estudos, n. 45, p. 15-36, 1996.; SCHOLZ, Roswitha. A teoria da dissociação sexual e a teoria crítica de Adorno. Disponível em: http://obeco.planetaclix.pt/ roswitha-scholz9.htm. Acesso em: 3 mar. 2021.

${ }^{41}$ BEAUVOIR, Simone de. O segundo sexo. São Paulo: Difusão Europeia do Livro, 1967.

${ }^{42}$ SANTOS, Rita; ROQUE, Sílvia; MOURA, Tatiana. Conexões perdidas: representações de género, violência (armada) e segurança na Resolução 1325. Revista Crítica de Ciências Sociais, n. 96, p. 165-196, 2012. p. 181.

${ }^{43}$ Com isso não se deve inferir que a inserção na lógica do valor é em si emancipatória, como será discutido adiante. 
bais, como o capitalismo, neocolonialismo e imperialismo (materializado, na sua forma mais extrema, nas intervenções militares estrangeiras), analisadas pelos feminismos pós-coloniais (Spivak, 1987; Eisenstein, 2004; Pratt, 2009), é revelador deste viés. ${ }^{44}$

Afinal, os direitos humanos são para todos e para todas ou apenas para todos? A lógica da Resolução $1325 / 2000$, como a de tantas (senão todas) as normas internacionais, é a neoliberal, que visa, apenas, integrar as mulheres ao mercado ${ }^{45}$, sem qualquer proposta realmente emancipatória e igualitária.

Além disso, no documento em tela, a desigualdade entre homens e mulheres é vista como um problema típico dos países pobres ou "em desenvolvimento", contribuindo para o aprofundar da desigualdade de poder entre Norte e Sul globais. Como demonstrado por Carvalho ${ }^{46}$, o Norte escreve sobre o Sul como se somente neste último houvesse violação a direitos humanos e a normas internacionais. O recorte feito neste artigo exemplifica essa desigualdade de tratamento, sem ignorar que outros recortes podem desnudar diferentes aspectos das injustiças em nível global.

Se o único problema da universalidade abstrata na forma mercadoria, que engloba também os direitos humanos na dimensão político-jurídica do fetiche moderno, fosse a representação androcêntrica, ter-se-ia uma complexidade menor no processo de análise. Porém:

o universalismo abstracto da modernidade é não
só androcêntrico, mas também ocidental. Tal como
uma grande parte da humanidade não ocidental
permaneceu marginal no sistema mundial da pro-
dução de mercadorias e não saiu do nível inferior
do desenvolvimento capitalista por causa do atraso
histórico, do mesmo modo também a generaliza-
ção global da forma de sujeito ocidental ficou ligada
a uma tendência sócio-cultural destrutiva e a uma
"classificação de segunda" tanto material como
simbólica. A concorrência universal inerente ao
moderno sistema produtor de mercadorias suscita
nos sujeitos actuantes a necessidade de imagens do
inimigo. Onde não se passa o limiar da crítica da
metafísica real moderna, os sujeitos transformam

${ }^{44}$ SANTOS, Rita; ROQUE, Sílvia; MOURA, Tatiana. Conexões perdidas: representações de género, violência (armada) e segurança na Resolução 1325. Revista Crítica de Ciências Sociais, n. 96, p. 165-196, 2012. p. 172.

45 SANTOS, Rita; ROQUE, Ś́lvia; MOURA, Tatiana. Conexões perdidas: representações de género, violência (armada) e segurança na Resolução 1325. Revista Crítica de Ciências Sociais, n. 96, p. 165-196, 2012. p. 183.

46 CARVALHO, Érica Rios de. Direitos humanos e dominação: a ONU no espelho. 2019. Tese (Doutorado em Políticas Sociais e Cidadania) - Universidade Católica do Salvador, Salvador, 2019. as suas experiências de sofrimento em projecções sobre contra-sujeitos, que são construídos como "sub-humanos" (de cor), ou como "super-homens negativos" (judeus). As ideologias do racismo e do anti-semitismo, tal como a ideologia do sexismo, estão assim estruturalmente referidas à metafísica real moderna. O sujeito universalista é essencialmente um sujeito masculino-branco-ocidental (MBO). A generalização da forma deste sujeito MBO leva a múltiplas refracções na consciência da humanidade extra-europeia e dos migrantes, com o que surgem novas misturas de sexismo, racismo ou "etnicismo" e anti-semitismo. ${ }^{47}$ (grifos nossos)

Não esquecendo essa complexidade, que demanda futuros estudos para mais adequada articulação, vale destacar que, desde o início do século XX até os dias atuais, apenas 30 países tiveram mulheres como Chefes de Estado em algum momento (entre eleitas democraticamente e rainhas)..$^{48}$ A rainha Elizabeth II responde, sozinha, por diversas dessas entradas.

Em 2015, quando a Declaração de Beijing — a mais recente dentre os documentos analisados - fazia 20 anos, apenas 18 países tinham mulheres à frente de seus governos ${ }^{49}$. Dessas, algumas sofreram impeachment nos anos que se seguiram, como foi o caso de Dilma Roussef $^{50}$, no Brasil, e de Park Geun-hye ${ }^{51}$, na Coréia do Sul. O que isso diz sobre a aceitabilidade de mulheres nos mais altos cargos de poder no mundo?

Em 2021, um total de 13 países contava com 50\% ou mais de mulheres ministras. ${ }^{52}$ Essa baixa representatividade feminina nas lideranças dos Estados tem evidentes consequências na formulação de agendas e no desenho de políticas prioritárias. Não se quer dizer, com isso, que homens não possam se interessar ou genuinamente

47 EXIT!. Crítica do capitalismo para o século XXI. Com Marx para além de Marx: o Projecto Teórico do Grupo EXIT!, p. 1-7, mar. 2007. Disponível em: http://obeco.planetaclix.pt/exit_projecto_teorico. htm. Acesso em: 20 ago. 2021.

48 Pode-se conferir as listas em: Lista de mulheres eleitas como chefes de Estado - Wikipédia, a enciclopédia livre (wikipedia.org) e Lista de rainhas reinantes - Wikipédia, a enciclopédia livre (wikipedia.org). Acesso em: 17 mar. 2021.

49 BBC. O pequeno grupo das mulheres que lideram países. Disponível em: $\mathrm{O}$ pequeno grupo das mulheres que lideram países - BBC News Brasil. Acesso em: 17 mar. 2021.

50 THE GUARDIAN. Dilma Rousseff impeachment: what you need to know. Disponível em: Dilma Rousseff impeachment: what you need to know - the Guardian briefing | Brazil | The Guardian. Acesso em: 17 mar. 2021.

51 BBC. Park Geun-bye: South Korea's ex-leader jailed for 24 years for corruption. Disponível em: Park Geun-hye: South Korea's exleader jailed for 24 years for corruption - BBC News. Acesso em: 17 mar. 2021.

52 UN WOMEN. Women in politics 2021. 2021. 
pretender proteger os direitos humanos das mulheres. Entretanto, a própria subjetividade de sua experiência masculina no mundo limita seus olhares e leituras sobre as demandas peculiares femininas. ${ }^{53}$

Esse contexto, discutido, neste artigo, com base no recorte dos três documentos mais relevantes do Direito Internacional acerca da proteção aos direitos humanos das mulheres, conduz a indagações sobre a própria legitimidade do Direito Internacional dos Direitos Humanos. Não são incômodos novos e nem restritos ao recorte de gênero eleito. Nesse diapasão, Buchanan ${ }^{54}$ enumera cinco principais desafios à legitimidade das instituições internacionais: (i) muitos órgãos internacionais são controlados por alguns poucos Estados poderosos; (ii) tais órgãos são injustos com indivíduos e grupos não-estatizados; (iii) questiona-se se cumprem de fato o papel que lhes é atribuído conforme as diretrizes publicamente desenhadas; (iv) a lei internacional foi muito acusada de não ser compatível com a soberania constitucional democrática de cada Estado - argumento superado dentro do próprio Direito Internacional; e (v) ausência de democracia dentro das instituições internacionais.

Em sua tese de doutorado, Carvalho ${ }^{55}$ aponta inúmeras falhas na estrutura, composição e atuação da ONU que corroboram as críticas de Buchanan ${ }^{56}$ à legitimidade de um Direito Internacional construído ali, especialmente debruçando-se sobre o Conselho de Direitos Humanos e o Conselho de Segurança do órgão. Ademais, atribuir tal legitimidade à premissa de que os Estados dão seu consentimento quando da formulação e adesão a normas internacionais (sejam elas sobre direitos humanos ou não) é um equívoco. Para além da atuação de atores não-estatais no âmbito da governança internacional ${ }^{57}$,

\footnotetext{
53 BEAUVOIR, Simone de. O segundo sexo. São Paulo: Difusão Europeia do Livro, 1967; BUTLER, Judith. Mecanismos psiquicos del poder. Valência: Ediciones Cátedra, 1997.

54 BUCHANAN, Allen. The legitimacy of international law. In: BESSON, Samantha; TASSIOULAS, John (org.). The philosophy of international law. Oxford: Oxford University Press, 2010.

55 CARVALHO, Érica Rios de. Direitos bumanos e dominação: a ONU no espelho. 2019. Tese (Doutorado em Políticas Sociais e Cidadania) - Universidade Católica do Salvador, Salvador, 2019.

${ }^{56}$ BUCHANAN, Allen. The legitimacy of international law. In: BESSON, Samantha; TASSIOULAS, John (org.). The philosophy of international law. Oxford: Oxford University Press, 2010.

57 BUCHANAN, Allen. The legitimacy of international law. In: BESSON, Samantha; TASSIOULAS, John (org.). The philosophy of international law. Oxford: Oxford University Press, 2010. p. 91.
}

[...] o consentimento dos Estados mais fracos nem sempre é substancialmente voluntário, uma vez que os Estados mais fortes podem tornar altos os custos do seu não consentimento. Além disso, em muitos casos, os Estados não representam todos ou mesmo a maioria dos seus povos, por não serem suficientemente democráticos. ${ }^{58}$

Assim, múltiplos elementos influenciam a questionável legitimidade do Direito Internacional dos Direitos Humanos. Há soluções apontadas por Leite e Lessa ${ }^{59}$ para vários desses questionamentos, mas o incômodo decorrente do eurocentrismo e androcentrismo não são afastados por tais propostas. Observa-se a continuidade das desigualdades entre homens e mulheres, para não mencionar uma constrangedora falta de articulação, ou de vontade de se articular, no sentido de estabelecer diálogos mais plurais com outros gêneros, orientações sexuais e performances, até o presente momento invisibilizados, ausentes do debate.

Os resultados desta pesquisa indicam, portanto, que os tensionamentos que já haviam sido levantados, por exemplo, pelas francesas autoras da Declaração de Direitos da Mulher e da Cidadã, de 1789, seguem válidos passados mais de 200 anos. Portanto, a comunidade epistêmica ${ }^{60}$ do Direito Internacional dos Direitos Humanos precisa não somente ser vista como relativa, como profundamente criticada como tal. Quem consentiu e vem consentindo nessa comunidade não inclui, geralmente, pelos resultados ora obtidos, as vozes e perspectivas das mulheres. Para elas é falado e por elas fala essa comunidade epistêmica internacional.

Por mais que se presuma a boa-fé dessa comunidade em buscar a igualdade mundial entre homens e mulheres, a revisão bibliográfica sobre a participação das mulheres nos espaços públicos de poder não permite arroubos de otimismo com documentos internacionais como os aqui discutidos. Em verdade, eles exprimem

58 LEITE, Filipe Greco de Marco; LESSA, Rafaela Ribeiro Zauli. O conceito de legitimidade aplicado ao direito internacional e suas instituições. In: BUSTAMANTE, Thomas da Rosa; POLIDO, Fabrício Bertini Pasquot (org.). Filosofia do direito internacional. São Paulo: Almedina, 2016. p. 151-177. p. 159.

${ }^{59}$ LEITE, Filipe Greco de Marco; LESSA, Rafaela Ribeiro Zauli. O conceito de legitimidade aplicado ao direito internacional e suas instituições. In: BUSTAMANTE, Thomas da Rosa; POLIDO, Fabrício Bertini Pasquot (org.). Filosofia do direito internacional. São Paulo: Almedina, 2016. p. 151-177.

${ }^{60}$ HAAS, Peter M. Epistemic communities and international policy coordination. International Organization, v. 46, n. 1, p. 1-35, 1992. Disponível em: https://www.jstor.org/stable/2706951. Acesso em: 20 jul. 2021. 
a continuidade das relações desiguais entre homens e mulheres em escala internacional.

\section{Considerações finais}

Os resultados deste artigo indicam a inaplicabilidade do conceito de universalidade no recorte, diante da insuficiente participação feminina na elaboração das normas, da sua linguagem androcêntrica e da rejeição concreta dos Estados membros a elas. Quando não impõem vetos e reservas aos documentos, sua adesão pouco se traduz em mudanças efetivas por meio de legislação interna e políticas públicas de combate real à desigualdade entre homens e mulheres. Dados foram trazidos nesse sentido, atestando a distância entre previsões genéricas, abstratas, sobre tal igualdade e a concretude da vida humana, da ocupação dos espaços de poder em esfera nacional e internacional.

Este trabalho não exauriu todas as normas e documentos internacionais que abordam temas relacionados a mulheres, mas, com base no recorte metodológico explicado no primeiro capítulo, verificou-se a Convenção sobre a Eliminação de Todas as Formas de Discriminação Contra a Mulher (ONU, 1979), a Declaração e Plataforma de Ação de Beijing (ONU, 1995) e a Resolução 1325/2000 do Conselho de Segurança da ONU sobre Mulheres, Paz e Segurança.

Com base na revisão bibliográfica e análise documental, foram atingidos os objetivos específicos de: (i) identificar o escopo dessas normas no seio da Organização das Nações Unidas (ONU) e (ii) discutir sua aceitação/rejeição pelos Estados membros, como indicador simbólico da amplitude da aplicabilidade do conceito de universalidade, que é um pressuposto na área do Direito Internacional dos Direitos Humanos.

Redigir direitos e políticas para mulheres sem ouvi-las, sem sua participação concreta, é no mínimo condescendente. Expressão cruel da contínua desigualdade entre homens e mulheres no cenário mundial, os documentos discutidos podem ser encarados como primeiros passos ou ao menos uma abertura de diálogo sobre o tema. Contudo, em pleno século XXI, seria inaceitavelmente pueril aplaudi-los ou tomá-los como significativos avanços rumo à isonomia entre homens e mulheres, sem ao menos ponderar sobre seus pontos problemáticos.
Uma comunidade epistêmica que exclua as mulheres, ou seja, aproximadamente metade da humanidade, não é suficiente, não é aceitável. Definitivamente, não é universal. Mesmo quando aparenta incluí-las, como fazem as previsões supostamente abstratas e universais dos tratados internacionais de direitos humanos, a realidade não permite ilusões sobre as injustiças a que as mulheres são submetidas.

Um olhar mais crítico se faz urgente, principalmente por parte de juristas que se limitam, não raro, a comemorar esse tipo de previsão abstrata, genérica, presumidamente universal, sem observar os dados sobre as muitas desigualdades e mazelas sociais que têm diante de si. Nessa linha, conforme comentado no primeiro capítulo deste artigo, há carência de estudos científicos no Brasil acerca da situação das mulheres no âmbito do Direito Internacional dos Direitos Humanos. No entanto, não faltam relatórios e documentos a serem examinados e discutidos nessa área, contrapondo teoria e prática e impondo uma revisão das premissas de universalidade acriticamente adotadas.

Se sobram críticas a serem feitas em relação à desigualdade entre homens e mulheres no do Direito Internacional dos Direitos Humanos, o vazio é ainda maior em relação à inclusão de outros gêneros, orientações sexuais e performances, até o presente momento invisibilizados, ausentes do debate e das pesquisas jurídicas sobre o tema.

Assim, este trabalho constitui uma forma de provocação, qual seja, a de que os dados disponíveis se convertam em escrita, interpretação e crítica, e que os dados, porventura indisponíveis, sem os quais o exercício crítico recua na direção do abstrato, por sua vez, sejam consolidados em novas e continuadas imersões em campo, reconhecendo-se que os objetos demandam um pensamento interseccional, complexo, intercultural.

\section{Referências}

AKOTIRENE, Carla. Interseccionalidade. São Paulo: Pólen, 2019.

BEAUVOIR, Simone de. O segundo sexo. São Paulo: Difusão Europeia do Livro, 1967.

BOBBIO, Norberto. A era dos direitos. São Paulo: Campus, 2004. 
BUCHANAN, Allen. The legitimacy of international law. In: BESSON, Samantha; TASSIOULAS, John (org.). The philosophy of international law. Oxford: Oxford University Press, 2010.

BUTLER, Judith. Actos performativos y constitución del género: un ensayo sobre fenomenologia y teoría feminista. In: CASE, Sue-Ellen (org.). Performing feminisms: feminist critical theory and theatre. [s.1.]: Johns Hopkins University Press, 1990. p. 270-282.

BUTLER, Judith. Gender trouble: feminism and the subversion of identity. New York: Routledge, 1990.

BUTLER, Judith. Mecanismos psíquicos del poder. Valência: Ediciones Cátedra, 1997.

CAMPBELL, Meghan. CEDAW and women's intersecting identities: a pioneering new approach to intersectional discrimination. Revista Direito GV, v. 11, n. 2, p. 479-504, 2015.

CARVALHO, Érica Rios de. Direitos humanos e dominação: a ONU no espelho. 2019. Tese (Doutorado em Políticas Sociais e Cidadania) - Universidade Católica do Salvador, Salvador, 2019.

CHINKIN, Christine; FREEMAN, Marsha. Introduction. In: FREEMAN, Marsha; CHINKIN, Chrstine; RUDOLF, Beate (org.). The UN Convention on the Elimination of All Forms of Discrimination Against Women: a commentary. [s.l.]: OUP, 2013.

EXIT!. Crítica do capitalismo para o século XXI. Com Marx para além de Marx: o Projecto Teórico do Grupo EXIT!, p. 1-7, mar. 2007. Disponível em: http://obeco. planetaclix.pt/exit_projecto_teorico.htm. Acesso em: 20 ago. 2021.

GENEVA DECLARATION. Lethal violence against women and girls. The Global Burden of Armed Violence, p. 87-120, 2015. Disponível em: http:/ /www.genevadeclaration.org/measurability/global-burden-of-armedviolence/global-burden-of-armed-violence-2015.html. Acesso em: 20 ago. 2021.

HAAS, Peter M. Epistemic communities and international policy coordination. International Organization, v. 46, n. 1, p. 1-35, 1992. Disponível em: https://www. jstor.org/stable/2706951. Acesso em: 20 jul. 2021.

HUNT, Lynn. A invenção dos direitos humanos: uma história. São Paulo: Companhia das Letras, 2009.
KROETZ, Flávia Saldanha. Between global consensus and local deviation: a critical approach on the universality of human rights, regional human rights systems, and cultural diversity. Revista de Investigações Constitucionais, v. 3, n. 1, p. 43-58, 2016. Disponível em: https://revistas. ufpr.br/rinc/article/view/45109. Acesso em: 15 mar. 2021.

LEITE, Filipe Greco de Marco; LESSA, Rafaela Ribeiro Zauli. O conceito de legitimidade aplicado ao direito internacional e suas instituições. In: BUSTAMANTE, Thomas da Rosa; POLIDO, Fabrício Bertini Pasquot (org.). Filosofia do direito internacional. São Paulo: Almedina, 2016. p. 151-177.

ONU. Conferência mundial sobre direitos humanos. Viena, 1993.

ONU. Convenção sobre a eliminação de todas as formas de discriminação contra a mulher. New York, 1979.

OXFAM. 5 ways women and girls have been the hardest hit by Covid-19. 2021. Disponível em: https://www.oxfam. org/en/5-ways-women-and-girls-have-been-hardesthit-covid-19. Acesso em: 20 ago. 2021.

OXFAM. Gender justice and women's rights. 2021. Disponível em: https://www.oxfam.org/en/what-we-do/ issues/gender-justice-and-womens-rights. Acesso em: 20 ago. 2021.

PRINCÍPIOS de Yogyakarta. 2006. Disponível em: http://www.dhnet.org.br/direitos/sos/gays/principios_de_yogyakarta.pdf. Acesso em: 20 ago. 2021.

RHODES, F.; BURNLEY, J.; DOLORES, M. Underpaid and undervalued: how inequality defines women $\square \mathrm{s}$ work in Asia $\square$. Oxford: OXFAM, 2016. Disponível em: http://policy-practice.oxfam.org.uk/publications/ underpaid-and-undervalued-how-inequality-defineswomens-work-in-asia-611297. Acesso em: 20 ago. 2021.

SANTOS, Boaventura de Sousa. A gramática do tempo: para uma nova cultura política. Porto: Afrontamento, 2006. p. 401-435.

SANTOS, Rita; ROQUE, Sílvia; MOURA, Tatiana. Conexões perdidas: representações de género, violência (armada) e segurança na Resolução 1325. Revista Crítica de Ciências Sociais, n. 96, p. 165-196, 2012.

SCHOLZ, Roswitha. A teoria da dissociação sexual e a teoria crítica de Adorno. Disponível em: http://obeco.planetaclix.pt/roswitha-scholz9.htm. Acesso em: 3 mar. 2021. 
SCHOLZ, Roswitha. O valor é o homem: teses sobre a socialização pelo valor e a relação entre os sexos. Novos Estudos, n. 45, p. 15-36, 1996.

SILVA, F. D. L.; I. FILHO, R. M.; SILVA, R. L. Direitos bumanos. Rio de Janeiro: SESES, 2016.

UN WOMEN. 2019-2020 Families in a changing world. New York, 2021. Disponível em: https://www.unwomen.org/-/media/headquarters/attachments/sections/library/publications/2019/poww-2019-factsheet-global-en.pdf?la $=$ en\&vs $=0$. Acesso em: 20 ago. 2021.

UN WOMEN. Report of the Secretary-General (2019): why addressing women's income and time poverty matters for sustainable development. New York, 2019. Disponível em: https://www.unwomen.org/en/digitallibrary/publications/2019/06/world-survey-on-therole-of-women-in-development-2019. Acesso em: 20 ago. 2021.

UN WOMEN. Women in politics 2021. 2021. 
Para publicar na Revista de Direito Internacional, acesse o endereço eletrônico www.rdi.uniceub.br ou www.brazilianjournal.org.

Observe as normas de publicação, para facilitar e agilizar o trabalho de edição. 